GEORGE IBRAHIM FARATH

\title{
UM ENSAIO SOBRE A AÇÃO DE DIREITO MATERIAL
}

Tese de Doutorado em Direito Civil

Orientador: Professor Doutor Alcides Tomasetti Jr.

Faculdade de Direito da Universidade de São Paulo

São Paulo

2014 


\section{UM ENSAIO SOBRE A AÇÃO DE DIREITO MATERIAL}

Tese depositada como requisito parcial para a obtenção do título de Doutor em Direito Civil pelo Programa de PósGraduação da Faculdade de Direito da Universidade de São Paulo, desenvolvida sob a orientação do Professor Doutor Alcides Tomasetti Jr.

Faculdade de Direito da Universidade de São Paulo São Paulo 
Banca Examinadora 


\section{ÍNDICE}

$\begin{array}{lr}\text { INTRODUÇÃO p. } 001 & \text { p }\end{array}$

CAPÍTULO I - A FENOMENOLOGIA DA JURIDICIZAÇÃO p. 003

$\begin{array}{lll}\text { I.1. A juridicização } & \text { p. } 003\end{array}$

I.2. Mundo total, mundo dos pensamentos, mundo jurídico p. 003

$\begin{array}{ll}\text { I.3. Norma jurídica p. } 005 & \text { p. }\end{array}$

$\begin{array}{lll}\text { I.4. Suporte fático p. } 006 & \text { p. }\end{array}$

$\begin{array}{ll}\text { I.5. Incidência jurídica } & \text { p. } 007\end{array}$

$\begin{array}{lll}\text { I.6. Subsunção, linguagem e autoridade } & \text { p. } 008\end{array}$

CAPÍTULO II - OS FATOS JURÍDICOS E SUA CLASSIFICAÇÃO p. 012

II.1. Elementos nucleares do suporte fático. A contrariedade a direito p. 012

$\begin{array}{lll}\text { II.2. Fatos jurídicos em sentido estrito } 014 & \text { p. } 014\end{array}$

$\begin{array}{lll}\text { II.3. Atos-fatos jurídicos p. } 015 & \text { p. }\end{array}$

$\begin{array}{lll}\text { II.4. Atos jurídicos em sentido amplo p. } 017 & \text { plo }\end{array}$

II.4.1. Atos jurídicos caracterizados pela contrariedade a direito p. 017

II.4.2. Atos jurídicos em abstrato permitidos pelo ordenamento p. 018

$\begin{array}{lll}\text { II.4.2.1. Negócios jurídicos p. } 018 & \text { p. }\end{array}$

II.4.2.2. Atos jurídicos em sentido estrito p. 020

II.4.2.3. Contrariedade a direito. Sanções invalidantes p. 020

II.4.2.4. Contrariedade a direito. Sanções ineficacizantes p. 023

II.5. Síntese sobre a classificação dos fatos jurídicos p. 025

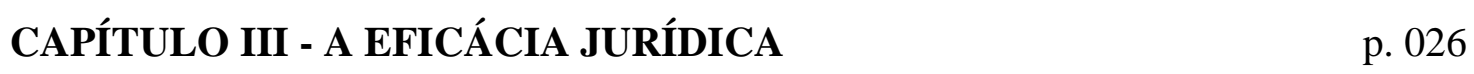

$\begin{array}{lll}\text { III.1. As situações jurídicas básicas } & \text { p. } 028\end{array}$

III.2. As situações jurídicas unissubjetivas 029

III.3 As situações jurídicas complexas ou intersubjetivas unilaterais p. 030

$\begin{array}{lll}\text { III.4 Outras situações jurídicas? } & \text { p. } 030\end{array}$

CAPÍTULO IV - A RELAÇÃO JURÍDICA (I) - Direitos e deveres;

$\begin{array}{ll}\text { pretensões e obrigações; direitos formativos e expectativos } & \text { p. } 033\end{array}$

$\begin{array}{lll}\text { IV.1 Direitos subjetivos e assubjetivados } & \text { p. } 033\end{array}$

IV.2 Direitos e deveres a uma prestação. Pretensões e obrigações p. 035

$\begin{array}{lll}\text { IV.2.1 Exigibilidade e adimplibilidade } & \text { p. } 039\end{array}$ 
$\begin{array}{lll}\text { IV.3 Poderes jurídicos. Direitos formativos e expectativos } & \text { p. } 040\end{array}$

IV.4 Direitos conexos a poderes jurídicos. Deveres de abstenção $\quad$ p. 044

IV.5 Direitos conexos a poderes jurídicos. Direito e pretensão à prática do ato constitutivo, modificativo, ou extintivo p. 047

\section{CAPÍTULO V - FATOS ILÍCITOS E RELAÇÃO JURÍDICA - Fatos}

$\begin{array}{ll}\text { ilícitos absolutos e relativos. Eficácia dos fatos ilícitos } 049 & \text { p. }\end{array}$

$\begin{array}{lll}\text { V.1 Fatos ilícitos absolutos } & \text { p. } 053\end{array}$

$\begin{array}{lll}\text { V.1.1 Fatos ilícitos absolutos indenizativos } & \text { p. } 055\end{array}$

V.1.2 Fatos Ilícitos absolutos dependentes e independentes p. 057

V.1.3 Fatos ilícitos absolutos e outros deveres de prestar p.064

$\begin{array}{lll}\text { V.1.4 Fatos ilícitos absolutos caducificantes } & \text { p. } 066\end{array}$

$\begin{array}{lll}\text { V.2 Fatos ilícitos relativos } & \text { p. } 068\end{array}$

V.2.1 Violação de pretensão e surgimento da ação de direito material p. 073

$\begin{array}{lll}\text { V.3 Ilícitos invalidantes e ilícitos absolutos caducificantes } & \text { p. } 074\end{array}$

V.4 Eficácia dos ilícitos e ação de direito material. Síntese p. 077

CAPÍTULO VI - A RELAÇÃO JURÍDICA (II) - Pretensão e ação de direito $\begin{array}{ll}\text { material } & \text { p. } 079\end{array}$

$\begin{array}{lll}\text { VI.1. Exigibilidade e cumprimento da prestação } 082 & \text { p. } 082 \text { p. }\end{array}$

VI.2 A ação de direito material, "parte da pretensão"? p. 087

CAPÍTULO VII - AÇÃO DE DIREITO MATERIAL E PRETENSÃO À $\begin{array}{lr}\text { TUTELA JURISDICIONAL DO DIREITO p. } 098 & \text { p. }\end{array}$

VII.1 Natureza e conteúdo da ação de direito material p. 099

$\begin{array}{lll}\text { VII.2 Pretensão à tutela jurisdicional da ação } & \text { p. } 104\end{array}$

$\begin{array}{lll}\text { VII.3 Ações declarativas } & \text { p. } 110\end{array}$

$\begin{array}{lll}\text { VII.4 Ações constitutivas } & \text { p. } 115\end{array}$

VII.5 Ações de direito material dependentes de execução p. 117

$\begin{array}{lll}\text { VII.5.1 Pretensão à tutela jurisdicional condenatória } & \text { p. } 121\end{array}$

VII.6 Pretensão à tutela jurisdicional mandamental - breves notas p. 124

CAPÍTULO VIII - OBSERVAÇÕES CONCLUSIVAS p. 125

$\begin{array}{ll}\text { RESUMO } & \text { p. } 127\end{array}$

$\begin{array}{lr}\text { RIASSUNTO } & \text { p. } 128\end{array}$

$\begin{array}{lr}\text { RÉSUMÉ } & \text { p. } 129\end{array}$

$\begin{array}{lr}\text { BIBLIOGRAFIA p. } 130 & \text { p. }\end{array}$ 


\section{INTRODUÇÃO}

A presente tese trata de tema atinente à Teoria Geral do Direito, mais precisamente à teoria geral da relação jurídica, analisando a ação de direito material.

A ação de direito material pode ser definida, estipulativamente, como o poder jurídico surgido a partir de um fato ilícito (mais frequentemente, a partir da violação de um direito). É neste sentido, aliás, que o art. 189 do Código Civil, referindo-se apenas à violação de um direito, emprega o termo pretensão.

Motivou-nos a escrever esta tese a percepção de que o monopólio estatal da justiça provocou mudanças no conteúdo da ação de direito material, já não sendo possível cogitar, v.g., de ações de direito material condenatórias, executivas ou mandamentais, seja por que algumas destas formas de tutela (condenatória e mandamental) não servem a realizar diretamente a ação de direito material (premindo, todavia, para o cumprimento da pretensão de direito material violada), seja, principalmente, porque os poderes necessários à realização da ação de direito material muitas vezes já não se compreendem na ação mesma.

Assim, embora a presente tese tenha como grande referencial teórico o sistema desenvolvido por F. C. PONTES DE MIRANDA (quem melhor tratou do tema entre nós), e embora consideremos a ação de direito material uma posição jurídica ineliminável do ordenamento, nossa percepção acabou determinando mudanças significativas no que tange à compreensão das ações de direito material, seja no que diz respeito ao conteúdo destas, seja ainda na necessária concepção de uma outra posição jurídica, uma pretensão conexa à ação de direito material e que tem por objeto os atos necessários à realização desta.

Versando sobre uma específica posição jurídica, a ação de direito material, será necessário à tese estabelecer: (i) sua existência (ou subsistência, nos ordenamentos modernos): (ii) sua natureza jurídica; (iii) o respectivo sujeito passivo; (iv) seu conteúdo; (v) sua eficácia; e (vi) a dinâmica entre a ação de direito material e as demais posições jurídicas predispostas, pelo ordenamento, para o exercício e a realização daquela ação. 
Para tanto, dividimos a tese em oito capítulos, o primeiro tratando da juridicização, o segundo dos fatos jurídicos (em sentido amplo), o terceiro da eficácia jurídica em geral, o quarto das relações jurídicas (mais precisamente, dos direitos a uma prestação e dos poderes jurídicos), o quinto do surgimento e eficácia dos fatos ilícitos (em sentido amplo), o sexto da relação entre a pretensão de direito material e a ação de direito material e o sétimo da conexão entre a ação de direito material e a pretensão à tutela jurídica da ação; por fim, o oitavo traz uma breve síntese das principais conclusões da tese. 


\section{CAPÍTULO VIII OBSERVAÇÕES CONCLUSIVAS}

Na Introdução à presente tese, observamos que seria necessário estabelecer: (i) a existência (ou subsistência) da ação de direito material num ordenamento moderno, já caracterizado pelo monopólio estatal da justiça; (ii) sua natureza jurídica; (iii) a respectiva titularidade passiva; (iv) seu conteúdo; (v) sua eficácia; e (vi) a dinâmica entre a ação de direito material e as demais posições jurídicas predispostas, pelo ordenamento, para o exercício e a realização daquela ação.

No que tange à subsistência desta posição jurídica, observamos (cf. Capítulo VII, seção VII.3 supra) que a ação de direito material é ineliminável do sistema jurídico, porquanto não é possível conceber-se que o sujeito A possa exigir, do Estado-juiz (ou do juízo arbitral), atos que determinem efeitos de direito material na esfera jurídica de outro jurisdicionado (B), sem prever um poder, titulado por A e dirigido a B, sujeitando este último aos efeitos pretendidos por $\mathrm{A}$ com a realização da prestação jurisdicional (e já previstos, antes desta realização).

Há aqui, manifestamente, duas relações jurídicas distintas: uma entre A e B, e outra entre A (agora como jurisdicionado) e o Estado, levando à necessária concepção de duas posições jurídicas, necessariamente distintas pelas relações em que se inserem e, como visto, distintas também pelos respectivos sujeitos passivos, e pelas respectivas naturezas jurídicas.

Como visto (cf. especialmente Capítulo VII, seção VII.1 supra), a ação de direito material é um poder jurídico, surgido para o respectivo titular em virtude do cometimento de um ilícito ${ }^{1}$, e dirigido contra o respectivo violador, ou um terceiro responsável, tendo por conteúdo a previsão dos efeitos de direito material que o titular desta ação pode impor ao respectivo sujeito passivo. À ação de direito material, que é espécie de poder jurídico, corresponde portanto uma sujeição.

Cf. Capítulo V, seções V.3 e V.4, supra. 
Por conta do monopólio estatal da justiça, normalmente a ação de direito material já não contém mais a legitimidade para que seu titular exerça os atos necessários à efetivação de sua respectiva ação, e nem mesmo contém a legitimidade para que o Estado os exerça. Uma vez que o poder jurídico se caracteriza pela possibilidade de alterar a esfera jurídica do sujeito passivo, este poder não precisa compreender, necessariamente, a legitimação para a prática do ato. O poder jurídico continua a existir, entre os mesmos sujeitos ativo e passivo, se seu titular pode exigir de terceiro o ato de que resultem alterações na esfera do sujeito passivo (cf. Capítulo IV, seção IV.5 supra).

Com o monopólio estatal da justiça, surge portanto uma pretensão voltada contra o Estado (não contra o sujeito passivo da ação de direito material!), tendo por objeto os atos necessários à efetivação da ação de direito material; em síntese, uma pretensão à tutela jurisdicional da ação (cf. especialmente o Capítulo VII, seção VII.2 supra). Assim, os efeitos previstos pela ação de direito material já não se irradiam do ato de exercício da ação pelo respectivo titular (exercício em geral consistente na dedução desta ação, e da respectiva pretensão à tutela jurisdicional, na demanda judicial), mas sim do ato estatal predisposto para tutela daquela ação.

É patente, como observado, a existência de duas relações jurídicas distintas, uma de direito material, entre A e B, caracterizada por um poder do primeiro (a ação de direito material) e sujeição do segundo, e outra de direito público, entre A (como jurisdicionado) e o Estado, tendo por objeto a concessão de tutela jurídica àquela ação (caso reconhecida existente).

A pretensão à tutela jurisdicional da ação é uma pretensão concreta, porque conexa a uma ação de direito material efetivamente existente. Todavia, nem a ação de direito material, nem a respectiva pretensão à tutela jurisdicional da ação excluem a existência de um outro direito, abstrato (porque independente da razão ou desrazão do autor), o direito fundamental à jurisdição, de que decorre o direito de demandar, em verdade um poder formativo gerador, porque enseja o surgimento da relação jurídica processual. Aliás, é este direito, abstrato, que permite o exercício das outras duas posições jurídicas, pela respectiva dedução na demanda e, no caso da pretensão à tutela jurisdicional da ação, pela exigência dos atos que constituem seu respectivo objeto. 


\section{RESUMO}

A presente tese tem por tema a ação de direito material, assim considerada o poder jurídico, de direito material, surgido a partir de um ilícito e voltado contra o respectivo causador (ou um terceiro responsável), tendo por conteúdo a previsão dos efeitos de direito material que seu titular pode impor ao violador, ainda que não diretamente, mas por meio do Estado-juiz, ou de outro órgão de aplicação do direito.

A tese analisa, portanto: (i) a existência (ou subsistência) da ação de direito material num ordenamento moderno, já caracterizado pelo monopólio estatal da justiça; (ii) sua natureza jurídica; (iii) seu respectivo sujeito passivo; (iv) seu conteúdo; (v) sua eficácia; e (vi) a dinâmica entre a ação de direito material e as demais posições jurídicas predispostas, pelo ordenamento, para o exercício e a realização daquela ação, notadamente o direito fundamental à jurisdição, de natureza abstrata, e a pretensão à tutela jurisdicional da ação, de natureza concreta.

PALAVRAS-CHAVE: Poder jurídico; Pretensão; Ação; Ação de direito material. 


\section{RIASSUNTO}

La presente tesi ha per oggetto l' azione di diritto sostanziale, così considerata il potere giuridico (di diritto sostanziale) nato da un' illecito e rivolto contro il loro causante (o un terzo responsabile), avente per contenuto la previsione degli effetti giuridici di diritto materiale que il titolare dall'azione può imporre il trasgressore, anche se non direttamente, ma attraverso lo Stato-giudice, o un'altro ente di applicazione della legge.

La tesi analisa, quindi: (i) l'esistenza (o la sussistenza) dell' azione di diritto sostanziale in un ordinamento giuridico moderno, già caratterizzato dal monopolio statale della giustizia; (ii) la sua natura giuridica; (iii) il rispettivo soggetto passivo; (iv) il suo contenuto; (v) la sua efficacia; e (vi) la dinamica tra l'azione di diritto sostanziale e le altre posizioni giuridiche predisposti, dall' ordinamento giuridico, per l'esercizio e la realizzazione di quella azione, in particolare il diritto fondamentale alla giurisdizione, di natura astratta, e la pretesa alla tutela giurisdizionale dell'azione, di natura concreta.

PAROLE-CHIAVE: Potere giuridico; Pretesa; Azione; Azione di diritto sostanziale. 


\section{RÉSUMÉ}

Cette thèse a per objet l'action de droit matériel, considéré comme le pouvoir juridique (appartenant au droit matériel), surgi d'un fait illicite et tourné contre leur provocateur (ou un tiers responsable), ayant par contenu la prévision des effets de droit matériel que le titulaire de l'action peut exiger de leur respectif sujet passif, même si pas directement, mais par moin de l'État-juge, ou par moin d'un autre organe d'application de la loi.

La thèse analyse, donc: (i) l'existence (ou la subsistance) de l'action de droit matériel dans un système juridique moderne, déjà caractérisé par le monopole de la justice par l'État; (ii) sa nature juridique; (iii) le respectif sujet passif; (iv) son contenu; (e) son efficacité; et (vi) la dynamique entre l'action de droit matériel et d'autres positions juridiques prédisposés, par le système juridique, pour l'exercice et la réalisation de cette action, notamment le droit fondamental à la juridiction, de nature abstraite, et la préténtion à la tutelle juridictionelle de l'action, de nature concrète.

MOTS-CLÈ: Pouvoir juridique; Préténtion; Action; Action de droit matériel. 


\section{BIBLIOGRAFIA}

BAPTISTA DA SILVA, Ovídio A. Comentários ao Código de Processo Civil. V. I (arts. $01^{\circ}$ a 100). 2. ed. São Paulo: RT, 2005.

GEN/Forense, 2008.

Curso de Processo Civil. V. I, tomo I. 8. ed. Rio de Janeiro:

GEN/Forense, 2008.

. Curso de Processo Civil. V. I, tomo II. 6. ed. Rio de Janeiro:

Direito material e processo. In: CARDOSO MACHADO, Fábio;

e RIZZO AMARAL, Guilherme (organizadores). Polêmica sobre a ação - a tutela jurisdicional na perspectiva das relações entre direito e processo. Porto Alegre: Livraria do Advogado Editor, 2006. p. 55-81.

. Direito subjetivo, pretensão de direito material e ação. In:

CARDOSO MACHADO, Fábio; e RIZZO AMARAL, Guilherme (organizadores). Polêmica sobre a ação - a tutela jurisdicional na perspectiva das relações entre direito e processo. Porto Alegre: Livraria do Advogado Editora, 2006, p. 15-39.

de Janeiro: Forense, 2007.

Jurisdição e execução na tradição romano-canônica. 3. ed. Rio

BARBOSA MOREIRA, José Carlos. Questões velhas e novas em matéria de classificação das sentenças. In: Temas de direito processual (oitava série). São Paulo, Saraiva, 2004, p. $125-141$.

BERNARDES DE MELLO, Marcos. Teoria do fato jurídico - plano da eficácia (1ª parte). 5. ed. São Paulo: Saraiva, 2009.

Paulo: Saraiva, 2013.

. Teoria do fato jurídico - plano da existência. 19. ed. São

BEVILAQUA, Clóvis. Código Civil dos Estados Unidos do Brazil commentado.V. I. [1. ed.]. Rio de Janeiro: Francisco Alves, 1916.

1929.

. Theoria geral do direito civil. 1. ed. Rio de Janeiro: Francisco Alves,

BOTELHO DE MESQUITA, José Ignácio. Da ação civil. São Paulo: RT, 1975.

Von BÜLOW, Oskar. La teoria de las excepciones procesales y los presupuestos procesales. Buenos Aires: EJEA, 1964.

BUZAID, Alfredo. A ação declaratória no direito brasileiro. 2. ed. São Paulo: Saraiva, 1986. 
CALMON DE PASSOS, José Joaquim. A ação no direito processual civil brasileiro. Salvador: Oficinas Gráficas da Imprensa Oficial da Bahia, 1960.

CHIOVENDA, Giuseppe. L' azione nel sistema dei diritti. Bologna: Zanichelli, 1903 (hoje, In: Saggi di diritto processuale civile (1894-1937). V. I. Milano, Giuffrè, 1993, p. 399).

Istituzioni di diritto processuale civile. Vv. I-II. 2. ed. Napoli: Jovene, 1935-1936 (= Instituições de direito processual civil. Vv. I-III. 2. ed. São Paulo: Saraiva, 1965).

Principii di diritto processuale civile. Napoli: Jovene, 1965.

CORRÊA TELLES. Doutrina das Acções (acompanhada do Exemplário de Libellos) Edição íntegra, annotada, de accordo com o Codigo Civil Brasileiro pelo advogado Dr. Pontes de Miranda. Rio de Janeiro: Jacintho Ribeiro dos Santos, 1918.

COUTO E SILVA, Clóvis V. A obrigação como processo. São Paulo: Bushatsky, 1976.

CRUZ E TUCCI, José Rogério. A 'causa petendi' no processo civil. 3. ed. São Paulo: RT, 2009.

DIDIER JR., Fredie. Pressupostos processuais e condições da ação - o juízo de admissibilidade do processo. 1. ed. São Paulo: Saraiva, 2005 ( $3^{\text {a }}$ tiragem, 2010).

DINAMARCO, Cândido Rangel. Instituições fundamentais do processo civil. 6. ed. São Paulo: Malheiros, 2009.

ENNECCERUS, Ludwig; NIPEERDEY, Hans Karl. Derecho civil (parte general). Tomo I (parte general), v. II, segunda parte. 3. ed (sobre a 39ª edição alemã). Barcelona: Bosch, 1981.

FALZEA, Angelo. Accertamento. In: Ricerche di teoria generale del diritto e di dogmatica giuridica. V. II (dogmatica giuridica). Milano: Giuffrè [1997], p. 195-230.

FONTES, André. A pretensão como situação jurídica subjetiva. Belo Horizonte: Del Rey, 2002.

GOMES CORRÊA, Fábio Peixinho. O objeto litigioso no processo civil. São Paulo, Quartier Latin, 2009.

HENNING, Fernando Alberto Corrêa. Ação concreta - relendo Wach e Chiovenda. Porto Alegre: Sergio Antonio Fabris Editor, 2000.

HOHFELD, Wesley Newcomb. "As relações jurídicas fundamentais contrastadas entre si”. In Os conceitos jurídicos fundamentais aplicados na argumentação judicial. Lisboa: Gulbenkian, 2008.

IBRAHIM FARATH, George. Pretensão e ação nas relações entre direito e processo. Trabalho de Conclusão de Curso apresentado no Curso de Especialização em Direito 
Processual Civil da Escola Superior da Procuradoria Geral do Estado de São Paulo. São Paulo: ESPGE, 2010.

LARENZ, Karl. Derecho civil - parte general. Madrid: Editorial Revista de Derecho Privado, 1978 (tradução da 03 ${ }^{\mathrm{a}}$ edição alemã).

Metodologia da Ciência do Direito. 3. ed. Lisboa: Gulbenkian, 1997.

LIEBMAN, Enrico Tullio. L' azione nella teoria del processo civile. In: Problemi del processo civile. Napoli: Morano [1962], p. 22-53.

. Manuale di diritto processuale civile. V. I. 4.ed.. Milano: Giuffrè, 1980 (= Manual de direito processual civil. V. I. 2. ed. Rio de Janeiro: Forense, 1985).

LUMIA, Giuseppe. Elementos de teoria e ideologia do Direito. São Paulo: Martins Fontes, 2003.

MARINONI, Luiz Guilherme. Da ação abstrata e uniforme à ação adequada à tutela dos direitos. In: CARDOSO MACHADO, Fábio; e RIZZO AMARAL, Guilherme (organizadores). Polêmica sobre a ação - a tutela jurisdicional na perspectiva das relações entre direito e processo. Porto Alegre: Livraria do Advogado Editor, 2006. p. 197-252.

. Técnica processual a tutela dos direitos. 3. Ed. São Paulo: RT, 2010.

. Teoria geral do processo. 4. ed. São Paulo: RT, 2010.

MOREIRA ALVES, José Carlos. Direito subjetivo, pretensão e ação. In: Revista de processo. Ano XII, v. 47. São Paulo: RT, jul-set. 1987.

A parte geral do projeto de Código Civil Brasileiro (subsídios históricos para o novo Código Civil Brasileiro). 2. ed. São paulo: Saraiva, 2003.

MOTTO, Alessandro. Poteri sostanziali e tutela giurisdizionale. Torino: Giappichelli, 2012.

MUTHER, Theodor. Sulla dottrina dell' actio romana, dell' odierno diritto di azione, della litiscontestatio e della successione singolare nelle obbligazioni. In: WINDSCHEID, Bernhard; MUTHER, Theodor. Polemica intorno all' actio. Firenze: Sansoni, 1954, p. 189-283.

NEVES, Celso. Estrutura fundamental do processo civil. [2. ed.] Rio de Janeiro: Forense, 1997.

ORESTANO, Riccardo. Azione: storia del problema. In: Azione, diritti soggettivi, persone giuridiche. Bologna: Il Mulino, 1978, p. 13-111.

ORSI, Luigi. Pretesa. In: Enciclopedia del diritto. V. XXXV. Torino: UTET, 1986.

PEDROSA NOGUEIRA, Pedro Henrique - Teoria da ação de direito material, Salvador, Podium, 2008. 
PONTES DE MIRANDA, Francisco Cavalcante. Comentários ao Código de Processo Civil. V. I. 2. ed.. Rio de Janeiro: Forense, 1979.

Janeiro: Forense, 1976.

. Comentários ao Código de Processo Civil. V. X. Rio de . Francisco Cavalcante. Pretensão à tutela jurídica, pretensão processual e pretensão objeto do litígio. In: Revista Forense. V. 171. Rio de Janeiro: Forense, 1957, p. 21-30.

. Relação jurídica processual. In: Repertório enciclopédico do direito brasileiro. V. XLVIII. Rio de Janeiro: Borsoi, s.d.

. Tratado das ações. V. I. 2. ed. São Paulo: RT, 1972.

. Tratado das ações. V. VI. São Paulo: RT, 1976.

Borsoi, 1970.

. Tratado de Direito Privado. V. I. 3. ed. Rio de Janeiro:

. Tratado de Direito Privado. V. II. 3. ed. Rio de Janeiro:

Borsoi, 1970.

Borsoi, 1970.

. Tratado de Direito Privado. V. III. 3. ed. Rio de Janeiro:

Borsoi, 1970.

. Tratado de Direito Privado. V. IV. 3. ed. Rio de Janeiro:

. Tratado de Direito Privado. V. V. 3. ed. Rio de Janeiro:

Borsoi, 1970.

Borsoi, 1970.

. Tratado de Direito Privado. V. VI. 3. ed. Rio de Janeiro:

Borsoi, 1971.

. Tratado de Direito Privado. V. XIV. 3. ed. Rio de Janeiro:

Borsoi, 1958.

. Tratado de Direito Privado. V. XXII. 2. ed. Rio de Janeiro:

. Tratado de Direito Privado. V. XXIV. 2. ed. Rio de Janeiro:

Borsoi, 1959.

Borsoi, 1959.

. Tratado de Direito Privado. V. XXV. 2. ed. Rio de Janeiro:

Borsoi, 1966.

. Tratado de Direito Privado. V. LIII. 2. ed. Rio de Janeiro: 
POPPER, Karl. Conhecimento objetivo: uma abordagem evolucionária. São Paulo: Itatiaia/EDUSP, 1975.

PUGLIATTI, Salvatore. Esecuzione forzata e diritto sostanziale. Milano: Giuffrè, 1935.

PUGLIESE, Giovanni. Actio e diritto subbiettivo. Milano: Giuffrè, 1939 (e reimpressão Napoli: Jovene, 2006).

UTET, 1958, p. 24-29.

Azione (diritto romano). In: Novissimo Digesto Italiano. V. II. Torino: . Diritto e processo nella esperienza romana. In: Scritti giuridici (1985-1995). Napoli: Jovene, 2007, p. 733-757. Introduzione. In: WINDSCHEID, Bernhard; MUTHER, Theodor. Polemica intorno all' actio. Firenze: Sansoni, 1954, p. XIII-XLVIII.

. 'Res corporales', 'res incorporales' e Il problema del diritto soggettivo. In: AA. VV.. Studi in onore di Vincenzo Arangio-Ruiz nel XLV anno del suo insegnamento. V. III. Napoli: Jovene, 1953, p. 223-260.

PUGLIESE, Giovanni; SITZIA, Francesco; VACCA, Letizia. Istituzioni di diritto romano. 3. ed. Torino: Giappichelli, 1991.

ROSENBERG, Leo. Tratado de derecho procesal civil. Vv. I-III. Buenos Aires, EJEA, 1955 .

SAVIGNY, Federico Carlo di. Sistema del diritto romano attuale. V. V. Torino: Unione Tipografico-Editrice, 1893.

SPERDUTI, Giuseppe. Contributo alla teoria delle situazione giuridiche soggettive. Milano: Giuffrè, 1944.

SOARES DA COSTA, Adriano. Teoria da incidência da norma jurídica. 2. ed. São Paulo: Malheiros, 2009.

THON. Augusto. Norma giuridica e diritto soggettivo. Padova: CEDAM, 1951.

TORNAGHI, Hélio. Comentários ao Código de Processo Civil. V. I (arts. 01º a 153). São Paulo: RT, 1974. . A relação processual penal. 2. ed. São Paulo: Saraiva, 1987.

von TUHR, Andreas. Derecho civil - teoria general del derecho civil alemán. V. III, tomo 2. Buenos Aires: Depalma, 1948.

VANZELLA, Rafael Domingues Faiardo. O contrato e os direitos reais. São Paulo: RT, 2012.

VILANOVA, Lourival. Causalidade e relação no Direito. 4. ed. São Paulo: RT, 2000. 
WACH, Adolf. Manual de derecho procesal civil. Tradução de Tomás A. Banzhaf. Vv. III. Buenos Aires: EJEA, 1977.

La pretensión de declaración - un aporte a la teoria de la pretensión de protección del derecho. Buenos Aires: EJEA, s./d.

WINDSCHEID, Bernhard. L' actio del diritto civile romano dal punto di vista del diritto odierno. In: WINDSCHEID, Bernhard; MUTHER, Theodor. Polemica intorno all' actio. Firenze: Sansoni, 1954, p. 03-188.

L' actio. Replica a Th. Muther. In: WINDSCHEID, Bernhard; MUTHER, Theodor. Polemica intorno all' actio. Firenze: Sansoni, 1954, p. 285-346.

Editrice, 1902.

Diritto delle Pandette. V. I, primeira parte. Torino, Unione Tipografico- 